\title{
Quality of life in the subacute period following a cervical traumatic spinal cord injury based on the initial severity of the injury: a prospective cohort study
}

\author{
Andréane Richard-Denis ${ }^{1,2} \cdot$ Cynthia Thompson ${ }^{2} \cdot$ Jean-Marc Mac-Thiong $^{1,2,3}$
}

Received: 27 January 2018 / Revised: 6 June 2018 / Accepted: 15 June 2018 / Published online: 3 July 2018

(c) International Spinal Cord Society 2018

\begin{abstract}
Study design Prospective cohort study.

Objectives To evaluate the relationship between quality of life (QOL) after a traumatic spinal cord injury (TSCI) and acute predictors, with a particular emphasis on the initial severity of the neurological injury. Secondarily, to compare the QOL after a TSCI with the general population.

Setting A single Level-1 SCI-trauma centre.

Methods A cohort of 119 individuals admitted after a cervical TSCI between April 2010 and September 2016 was studied. QOL was assessed using the SF-36v2 questionnaire 6-12 months following the injury, and compared to the general population. The relationship between the initial severity of the neurological injury and the SF-36 summary scores was assessed using linear multivariable regression analyses.

Results Individuals sustaining less severe neurological injury (grade D) exhibited higher PCS than individuals with grades $\mathrm{A}, \mathrm{B}$ or $\mathrm{C}$ injury. Individuals with initial grade A injury showed increased MCS than individuals with incomplete grade B, C or D injury, with $42.9 \%$ scoring higher than the general population. The initial grade was significantly associated with chronic PCS and MCS.

Conclusions The initial severity of the neurological injury after a cervical TSCI may be used to estimate QOL in the subacute period following the injury. Individuals with complete tetraplegia may report good mental QOL despite severe physical impairment. Our findings could help clinicians to determine realistic expectations for patients in terms of QOL, and optimize the rehabilitation plan based on the initial evaluation after a TSCI.
\end{abstract}

\section{Introduction}

Traumatic spinal cord injuries (TSCI) lead to severe neurological deficits and functional limitations [1]. Accurate estimation of the future outcome early after the injury is of utmost importance [2]. In fact, clinicians working in acute

Andréane Richard-Denis

andreane.rdenis@gmail.com

1 Hôpital du Sacré-Cœur de Montréal, 5400 Gouin Boul. West, Montreal, QC H4J 1C5, Canada

2 Faculty of Medicine, University of Montreal, Pavillon RogerGaudry, S-749, C.P. 6128, succ. Centre-ville, Montreal, QC H3C 3J7, Canada

3 Sainte-Justine University Hospital Research Center, 3175 Chemin de la Côte-Sainte-Catherine, Montréal, QC H3T 1C5, Canada trauma hospitals need to discuss with patients and their families about the neurological deficits and potential for recovery early after the injury [3]. Moreover, the medical and surgical management also greatly depends on the longterm prognosis of patients. This is particularly true in cervical TSCI leading to severe functional deficits in the setting of tetraplegia. While neurological and functional outcomes after a TSCI have been widely studied $[2,4,5]$, studies on quality of life (QOL) are more sparse because predicting long-term QOL is highly complex. Indeed, QOL is a multidimensional phenomenon defined by the World Health Organization as "an individual's perception of their position in life in the context of the culture and value systems in which they live and in relation to their goals, expectations, standards and concerns" [6], consisting in the evaluation of a person's life as a whole [7, 8]. Therefore, QOL may provide a broad bio-psychosocial aspect of the outcome in a more holistic way than the neurological and functional aspects. 
189 patients with T-SCI were initially included

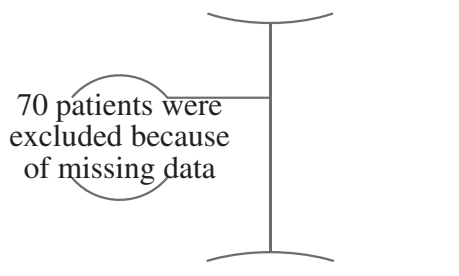

119 patients completed the follow-up

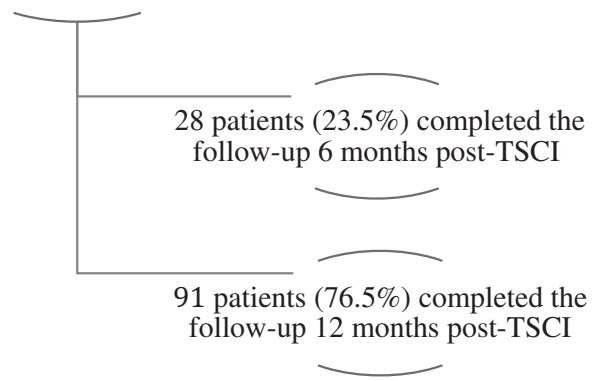

Fig. 1 Description of the inclusion process of patients in this prospective study

While the initial severity of the injury (American Spinal Injury Impairment Scale or AIS grade) is recognized as the main predictive factor of long-term functional and neurological outcomes following a TSCI $[2,9]$, its association with QOL remains largely unclear. Up to now, an association between QOL and the severity of the neurological deficits after an SCI has only been found when both aspects are assessed simultaneously during the chronic phase [10-13]. Kivisild et al. [14] evaluated the relationship between the completeness of the SCI in the acute phase and chronic QOL, but they only adjusted their regression analyses for age and gender, thus failing to consider other potential predictors available at the initial evaluation following TSCI.

It remains difficult for clinicians to estimate future QOL early after a TSCI based on the initial severity of the injury, while taking into account other potential acute predictors of mid to long-term QOL. Accurate estimation of QOL based on acute predictors could facilitate interactions between caregivers, optimize the elaboration of a coordinated rehabilitation plan and improve counselling for patients and their families [11]. Accordingly, this study aims to evaluate the relationship between QOL 6-12 months after a cervical TSCI and the initial severity of the neurological injury, while accounting for other potential predictors collected at admission of acute care. Secondarily, we compared the QOL for our cohort of cervical TSCI patients with mean normative QOL observed in the general Canadian population.

\section{Methods}

\section{Subjects}

A total of 189 patients with a cervical TSCI were admitted between April 2010 and September 2016 in an acute Level I SCI-specialized trauma centre (Hôpital SacréCoeur de Montréal, Quebec, Canada) were potentially eligible. After consenting to enrol in the study, patients were followed prospectively during inpatient care and at the outpatient clinic appointments after discharge. Patients were included in the study if they sustained an acute TSCI at the cervical level $(\mathrm{C} 1-\mathrm{C} 8)$ requiring surgical management at our institution, were aged 16 years or older, and attended the follow-up visits between 6 and 12 months post-SCI. Subjects were excluded if they had a penetrating trauma since these individuals are generally managed differently, as opposed to the general TSCI population. A total of 70 patients were excluded because they were loss to follow-up (Fig. 1). The study was approved by the institutional review board and all patients were enroled on a voluntary basis.

\section{Data collection}

Socio-demographic, clinical and trauma-related data were collected prospectively during the acute care hospitalization. Socio-demographic data included age, sex, household income $(<40,000 \$ ; 40,000-100,000 \$ ;>100,000 \$)$, employment status (active worker vs. unemployed/retired/ student), education level (less than college vs. college or beyond) and household status (alone vs. living with spouse vs. living with family member other than spouse). Household income was subdivided based on subgroups frequently used by Statistics Canada for the population of Quebec [15]. The severity of the TSCI was assessed upon arrival to the SCI-centre and was reported using the American Spinal Injury Association (ASIA) impairment scale (AIS) grade (A to D), according to the International Standards for Neurological Classification of Spinal Cord Injury (ISNCSCI) [16]. The neurological level of injury was dichotomized as high tetraplegia $(\mathrm{C} 1-\mathrm{C} 4)$ or low tetraplegia $(\mathrm{C} 5-\mathrm{C} 8)$. Trauma severity and the presence of associated injuries were assessed using the Injury Severity Score (ISS) [17]. The presence of concomitant traumatic brain injury (TBI) was also documented. The burden of comorbidities was also assessed using the Charlson Comorbidity Index (CCI), which weighs 19 comorbidities based on the adjusted relative risk of 1-year mortality and assigns them a score from 1 (conditions with a smaller relative risk; e.g. myocardial infarct) to 6 (conditions with a higher relative risk; e.g. AIDS) [18]. 


\section{Outcome assessment}

As a theoretical concept, QOL is a complex and dynamic phenomenon that has no simple single definition [19]. Few concepts in healthcare are often used to define the concept of QOL as a qualitative measure [20]. As mentioned in the introduction section, this study will use the concept of health-related QOL defined by the World Health Organization as "an individual's perception of their position in life in the context of the culture and value systems in which they live and in relation to their goals, expectations, standards and concerns" [6]. We thus used the multidimensional health-related QOL measure, the SF-36v2 questionnaire as our main outcome measure. The SF-36v2 is a valid and reliable tool that is widely used $[13,20]$. The SF-36v2 consists of 36 items assessing eight distinct health domains, which are physically and emotionally based: [21]

1. Physical functioning (PF; limitations in performing physical activities)

2. Role physical (RP; limitations in typical role activities due to physical health problems)

3. Body pain (BP; limitations in usual activities due to pain)

4. General health $(\mathrm{GH}$; one's perceptions of overall health)

5. Vitality (VT; feelings of energy/fatigue)

6. Social functioning (SF; interference of physical or emotional problems in performing social activities)

7. Role emotional (RE; limitations in typical role activities due to emotional problems)

8. Mental health (MH; emotional and cognitive wellbeing).

Two summary scores can be derived, one for the physical component score (PCS) and the other for the mental component score (MCS). PCS is derived from the scores on the $\mathrm{PF}, \mathrm{RP}, \mathrm{BP}$ and GH domains, whereas the MCS is calculated using the VT, SF, RE and MH subscores [13, 21]. The eight individual domain scores range between 0 and 100, and the component summary scores (PCS and MCS) are standardized around a mean of 50 (standard deviation of 10) for the norm-based scoring according to the general US population, using the software provided by Optum (Eden Prairie, MN, USA). The SF-36v2 was administered at the routine follow-up visit between 6 and 12 months after the trauma.

\section{Statistical analyses}

Non-parametric analyses were used since the distribution was not normal for independent variables according to the Kolmogorov-Smirnov tests. Direct comparisons for each individual domain and component summary scores between individuals based on the initial AIS grade (A vs. B vs. C vs. D) were performed using Kruskal-Wallis $H$ tests followed by post-hoc tests with pairwise comparisons in case of rejection of the null hypothesis (group similarity). The level of significance was not corrected for multiple testing, considering that such a correction may lead to significant weaknesses (for instance increased type 2 error) and should not be used unless it is imperative to avoid type 1 error or a general null hypothesis (all null hypotheses are true simultaneously) is required, which is not the case in this study $[22,23]$. Continuous data were reported as means \pm standard deviation (SD) as well as median and interquartile range (IQR), while categorical data were presented as percentages. The proportion of cervical TSCI patients with PCS and/or MCS reaching the mean normative PCS and/or MCS observed in the general Canadian population [24] (PCS: $<50.5$ vs. $\geq 50.5$; MCS: $<51.7$ vs. 251.7$)$ was also compared based on each initial AIS grade using $\chi^{2}$ tests.

As noted in Table 1, a non-negligible proportion of patients $(30 \%=36 / 119$ subjects) refused to provide information pertaining to some socio-demographic characteristics, particularly the household income, employment status, education level and household status. Individuals with complete data (83 subjects) and incomplete data (36 subjects) were similar in terms of all baseline characteristics (socio-demographic, initial trauma and clinical evolution), except for a higher proportion of women who did not provide information with regard to household income, employment status, education level and household status. There were $37 \%$ females in the group that did not answer all questions, as compared to $16 \%$ females in the group that answered all questions $(p=0.01)$.

Considering the presence of missing data for 36 subjects (for the independent variables), multiple (10) imputation analysis was performed using a Markov chain Monte Carlo (MCMC) algorithm. General linear models (GLM with identity link) were performed on the imputed cohort since the distribution of the standard error was normally distributed for our data. GLMs were first used to analyze the relationship between the initial severity of the TSCI (AIS grade) and the PCS (as the dependent variable). Then, a second GLM was performed to adjust for important confounding variables: (1) age; (2) gender; (3) neurological level of injury; (4) ISS; (5) presence of concomitant TBI; (6) CCI; (7) education level; (8) household income; (9) employment status; (10) household status. The same process was done for MCS (as dependant variable).

All statistical analyses were performed using the IBM SPSS Statistics 21 software (Chicago, IL), and the level of significance was 0.05 . We certify that all applicable institutional and governmental regulations concerning the 
Table 1 Baseline characteristics of the final cohort and comparison of individuals who completed the study $(N=119)$ and individuals who were loss to follow-up $(n=70)$

\begin{tabular}{|c|c|c|c|c|c|c|}
\hline & & & $\begin{array}{l}\text { Final cohort } \\
(n=119)\end{array}$ & $\begin{array}{l}\text { Loss to } \mathrm{FU} \\
(n=70)\end{array}$ & $\begin{array}{l}\text { FU } \\
6 \text { months }(n \\
=28)\end{array}$ & $\begin{array}{l}\text { FU } \\
12 \text { months } \\
(n=91)\end{array}$ \\
\hline \multirow[t]{6}{*}{$\begin{array}{l}\text { Socio- } \\
\text { demo } \\
\text { graphic }\end{array}$} & Age & $\begin{array}{l}\text { Mean (SD) } \\
\text { Median (IQR) }\end{array}$ & $\begin{array}{l}51.7(18.0)^{*} \\
55.0(37.0- \\
65.0)^{*}\end{array}$ & $\begin{array}{l}60.7(17.9)^{*} \\
63.0 \\
(51.0-75.0)^{*}\end{array}$ & $\begin{array}{l}55.4(15.9) \\
56.5 \\
(47.3-69.0)\end{array}$ & $\begin{array}{l}50.5(18.5) \\
54.0 \\
(35.0-65.0)\end{array}$ \\
\hline & Sex & $\%$ Male & 78.2 & 81.4 & 75.0 & 79.1 \\
\hline & $\begin{array}{l}\text { Household } \\
\text { income }\end{array}$ & $\begin{array}{l}\% 0-40,000 \$ \\
\% \\
40,000-100,000 \$ \\
\%>100,000 \$ \\
\% \text { Unknown }\end{array}$ & $\begin{array}{l}36.9 \\
50.0 \\
13.1 \\
29.4\end{array}$ & $\begin{array}{l}47.5 \\
42.5 \\
10.0 \\
42.8\end{array}$ & $\begin{array}{l}52.6 \\
36.8 \\
10.5\end{array}$ & $\begin{array}{l}32.8 \\
53.1 \\
14.1\end{array}$ \\
\hline & $\begin{array}{l}\text { Employment } \\
\text { status }\end{array}$ & $\begin{array}{l}\% \text { Active worker } \\
\% \text { Unemployed, } \\
\text { student, or retired } \\
\% \text { Unknown }\end{array}$ & $\begin{array}{l}54.2^{*} \\
45.8^{*} \\
0.01 *\end{array}$ & $\begin{array}{l}31.0^{*} \\
69.0^{*} \\
0.8^{*}\end{array}$ & $\begin{array}{l}55.6 \\
44.4\end{array}$ & $\begin{array}{l}53.8 \\
46.2\end{array}$ \\
\hline & Education level & $\begin{array}{l}\% \text { Less than } \\
\text { college } \\
\% \text { More than } \\
\text { college } \\
\% \text { Unknown }\end{array}$ & $\begin{array}{l}65.5 \\
34.5 \\
15.7\end{array}$ & $\begin{array}{l}66.1 \\
33.9 \\
0.08\end{array}$ & $\begin{array}{l}72.0 \\
28.0\end{array}$ & $\begin{array}{l}63.5 \\
36.5\end{array}$ \\
\hline & Marital status & $\begin{array}{l}\% \text { Living alone } \\
\% \text { Spouse/Partner } \\
\% \text { Family } \\
\text { member or other } \\
\% \text { Unknown }\end{array}$ & $\begin{array}{l}27.1 \\
50.8 \\
22.0 \\
0.01\end{array}$ & $\begin{array}{l}39.0 \\
50.8 \\
10.2 \\
15.7\end{array}$ & $\begin{array}{l}35.7 \\
39.3 \\
25.0\end{array}$ & $\begin{array}{l}24.4 \\
54.4 \\
21.1\end{array}$ \\
\hline \multirow[t]{4}{*}{$\begin{array}{l}\text { Initial } \\
\text { trauma }\end{array}$} & AIS grade & $\begin{array}{l}\% \mathrm{~A} \\
\% \mathrm{~B} \\
\% \mathrm{C} \\
\% \mathrm{D}\end{array}$ & $\begin{array}{l}15.0 \\
10.9 \\
16.0 \\
49.6\end{array}$ & $\begin{array}{l}8.6 \\
11.8 \\
14.7 \\
50.0\end{array}$ & $\begin{array}{l}17.9 \\
14.3 \\
17.9 \\
50.0\end{array}$ & $\begin{array}{l}25.3 \\
9.9 \\
15.4 \\
49.5\end{array}$ \\
\hline & NLI & $\% \mathrm{C} 1-\mathrm{C} 4$ & 50.9 & 63.1 & 51.9 & 50.6 \\
\hline & ISS & $\begin{array}{l}\text { Mean (SD) } \\
\text { Median (IQR) }\end{array}$ & $\begin{array}{l}21.8(9.3) \\
17.0 \\
(17.0-25.0)\end{array}$ & $\begin{array}{l}23.6(13.2) \\
20.0 \\
(17.0-25.0)\end{array}$ & $\begin{array}{l}21.9(6.6) \\
21.0 \\
(17.0-26.0)\end{array}$ & $\begin{array}{l}21.6(10.0) \\
17.0 \\
(16.0-25.0)\end{array}$ \\
\hline & $\begin{array}{l}\text { Presence of } \\
\text { concomitant } \\
\text { traumatic brain } \\
\text { injury }(\%)\end{array}$ & 57.9 & 56.5 & 68.0 & 55.1 & \\
\hline $\begin{array}{l}\text { Clinical } \\
\text { evolution }\end{array}$ & $\begin{array}{l}\text { Charlson } \\
\text { Comorbidity } \\
\text { Index }\end{array}$ & $\begin{array}{ll}\% & 0 \\
\% & 1 \\
\% & 2 \\
\% & 3 \\
\% & 4 \\
\% & 5 \\
\% & 6\end{array}$ & $\begin{array}{l}76.5 \\
10.1 \\
8.4 \\
3.4 \\
0.8 \\
0.0 \\
0.8\end{array}$ & $\begin{array}{l}62.9 \\
15.7 \\
10.0 \\
10.0 \\
1.4 \\
0.0 \\
0.0\end{array}$ & $\begin{array}{l}67.9 \\
14.3 \\
10.7 \\
7.1 \\
0.0 \\
0.0 \\
0.0\end{array}$ & $\begin{array}{l}79.1 \\
8.8 \\
7.7 \\
2.2 \\
1.1 \\
0.0 \\
0.8\end{array}$ \\
\hline
\end{tabular}

$\overline{I Q R}$ interquartile range, AIS ASIA Impairment Scale, NLI neurological level of injury, ISS injury severity score

${ }^{*} p$ is significant if $<0.05$ ethical use of human volunteers were followed during the course of this research.

\section{Results}

Table 1 presents the baseline characteristics of the cohort, including socio-demographic, traumatic and clinical characteristics. A total of 189 patients (150 males and 39 females; mean age \pm SD: $55.1 \pm 18.5$ years old) were admitted for a TSCI in our centre between April 2010 and September 2016, while 70 (37\%) subjects were loss to follow-up. Losses to follow-up were significantly older and more likely to be unemployed (Table 1). The final cohort therefore consisted of 119 subjects: 93 males and 26 females with a mean age of $51.7 \pm 18.0$ years.

SF-36v2 scores were obtained 1 year after the TSCI for 91 patients $(77 \%)$ and 6 months after the TSCI for 28 
Table 2 Physical domain and summary scores derived from SF-36v2 based on initial AIS grade (median; interquartile range)

\begin{tabular}{lllllll}
\hline Domain & & AIS A $(N=28)$ & AIS B $(N=13)$ & AIS C $(N=19)$ & AIS D $(N=59)$ & All TSCI $(N=119)$ \\
\hline PF $^{\S}$ & Mean (SD) & $23.4(10.0)$ & $25.4(9.5)$ & $29.8(11.1)$ & $40.5^{* *}(10.5)$ & $33.3(12.7)$ \\
& Median (IQR) & $19.3(19.3-21.7)$ & $21.2(19.3-28.8)$ & $28.8(19.3-36.5)$ & $40.3^{* *}(31.9-49.9)$ & $31.1(19.3-44.2)$ \\
$\mathrm{RP}^{\S}$ & Mean (SD) & $30.6(13.5)$ & $28.1(10.5)$ & $28.0(9.6)$ & $35.6^{*}(10.7)$ & $32.4(11.6)$ \\
& Median (IQR) & $21.2(21.2-41.4)$ & $21.2(21.2-31.3)$ & $21.2(21.2-34.7)$ & $36.2^{*}(26.8-40.3)$ & $30.2(21.2-39.2)$ \\
$\mathrm{BP}$ & Mean (SD) & $38.4(11.2)$ & $44.2(6.6)$ & $45.6(10.5)$ & $41.2(8.5)$ & $41.6(9.5)$ \\
& Median (IQR) & $39.0(29.2-47.5)$ & $42.6(42.6-44.7)$ & $46.7(38.6-51.5)$ & $42.6(34.4-47.5)$ & $42.6(34.6-47.5)$ \\
$\mathrm{GH}$ & Mean (SD) & $46.3(6.7)$ & $47.7(6.3)$ & $47.1(6.2)$ & $45.4(5.6)$ & $46.1(6.0)$ \\
& Median (IQR) & $45.6(42.1-50.1)$ & $47.5(42.0-53.2)$ & $48.4(45.1-50.8)$ & $46.1(40.8-49.1)$ & $46.1(41.3-49.9)$ \\
PCS & Mean (SD) & $31.4(7.5)$ & $35.1(6.7)$ & $37.3(6.8)$ & $41.4^{* *}(5.4)$ & $37.7(7.4)$ \\
& Median (IQR) & $32.7(27.4-37.6)$ & $36.3(30.2-39.7)$ & $36.6(32.5-40.9)$ & $42.4^{* *}(38.3-46.0)$ & $38.7(32.5-42.9)$ \\
\hline
\end{tabular}

$P F$ physical functioning, $R P$ role physical, $B P$ body pain, $G H$ general health, $P C S$ physical component summary

${ }^{\S}$ Kruskal-Wallis $H$ test, $p<0.05$

*Post-hoc test, $p<0.0$

Table 3 Mental domain and summary scores derived from SF-36v2 based on initial AIS grade (median; interquartile range)

\begin{tabular}{lllllll}
\hline Domain & & AIS A $(N=28)$ & AIS B $(N=13)$ & AIS C $(N=19)$ & AIS D $(N=59)$ & All TSCI $(N=119)$ \\
\hline VT & Mean (SD) & $46.5(4.9)$ & $44.6(5.1)$ & $44.3(6.4)$ & $43.6(4.6)$ & $44.5(5.1)$ \\
& Median (IQR) & $46.7(40.7-49.6)$ & $43.7(40.7-49.6)$ & $43.7(40.7-49.6)$ & $43.7(40.7-46.7)$ & $43.7(40.7-46.7)$ \\
SF & Mean (SD) & $36.1(5.2)$ & $38.4(2.2)$ & $37.0(6.8)$ & $36.6(4.7)$ & $36.8(5.0)$ \\
& Median (IQR) & $37.3(32.3-37.3)$ & $37.3(37.3-39.8)$ & $37.3(32.3-42.3)$ & $37.3(32.3-37.3)$ & $37.3(32.3-37.3)$ \\
RE & Mean (SD) & $38.8(19.5)$ & $32.9(15.7)$ & $30.5(15.8)$ & $38.9(13.8)$ & $36.8(16.0)$ \\
& Median (IQR) & $50.9(14.4-56.2)$ & $35.3(16.1-45.7)$ & $24.8(14.4-45.7)$ & $35.3(26.6-54.4)$ & $35.3(24.8-56.2)$ \\
MH & Mean (SD) & $41.9(5.1)$ & $39.0(4.8)$ & $40.8(4.8)$ & $39.4(4.0)$ & $40.1(4.6)$ \\
& Median (IQR) & $43.0(37.8-45.6)$ & $40.4(33.9-43.0)$ & $40.4(37.8-45.6)$ & $37.8(36.5-43.0)$ & $40.6(35.6-46.2)$ \\
MCS & Mean (SD) & $46.2^{*}(9.3)$ & $41.8(7.4)$ & $40.1(7.7)$ & $39.8(5.6)$ & $41.5(7.5)$ \\
& Median (IQR) & $46.6 *(37.9-55.1)$ & $43.5(36.0-48.4)$ & $37.4(33.4-47.7)$ & $39.5(35.4-44.2)$ & $40.6(35.6-46.2)$ \\
\hline
\end{tabular}

$V T$ vitality, $S F$ social functioning, $R E$ role emotional, $M H$ mental health, $M C S$ mental component summary

${ }^{\S}$ Kruskal-Wallis $H$ test, $p<0.05$

*Post-hoc test, $p<0.05$

patients (24\%). Baseline characteristics were similar between these patients $(p>0.05)$ (Table 1). Table 2 shows the PCS and associated subscores (PF, RP, BP and GH) for all patients according to the initial AIS grade. A Kruskal-Wallis $H$ test revealed statistically significant differences for PCS $\left(H=38.238 ; p<10^{-3}\right)$, PF $(H=47.696$; $\left.p<10^{-3}\right)$ and RP $(H=16.408 ; p=0.001)$ based on the initial AIS grade. Post-hoc tests showed that PF and PCS were 10-20 points higher with an initial AIS D SCI, when compared with more severe AIS A, B and C grades $(p<$ $0.05)$. Post-hoc tests also showed that RP was increased in AIS D injury, reaching statistical significance when compared to AIS A and C injuries $(p<0.05)$.

Table 3 presents the MCS and associated subscores (VT, $\mathrm{SF}, \mathrm{RE}$ and $\mathrm{MH}$ ) according to the initial AIS grade. The Kruskal-Wallis $H$ test revealed a significant difference in MCS $(H=11.195 ; p<0.05)$, while there were no differences observed for the four subscores contributing to the
MCS. Post-hoc tests showed that MCS was significantly increased in AIS A SCI when compared with AIS D SCI ( $p$ $<0.05)$.

Only one patient with AIS C injury (1\% of entire cohort) reached a PCS higher than the average Canadian PCS (PCS $\geq 50.5$ ) [24]. Conversely, 16 patients (13\%) scored higher than the average Canadian MCS (MCS $\geq 51.7$ ), including 12 patients presenting with AIS A injury [24]. The proportion of patients with a MCS higher than the average Canadian MCS was significantly increased for AIS A injury when compared to AIS B, C and D injuries $\left(X^{2}=\right.$ $28.322 ; p<10^{-3}$ ): $43 \%$ for AIS A vs. $8 \%, 10.6 \%$ and $2 \%$ for AIS B, C and D, respectively.

The GLM showed that more severe initial AIS grade was significantly associated with lower PCS (Table 4). This model was significant ( $p=0.01$ ), and explained $38 \%$ of the variance in PCS $\left(R^{2}=0.381\right)$. The initial AIS grade was also significantly associated with MCS in the GLM, but in 
Table 4 Relationship between the initial severity of the spinal cord injury and (1) the physical component score (PCS) and (2) the mental component score (MCS): results of the general linear models $(N=119)$

\begin{tabular}{lllll}
\hline Dependant variable & Independent variable & & $\beta_{\text {raw }}(95 \% \mathrm{CI})$ & $\beta_{\text {adjusted* }}(95 \% \mathrm{CI})$ \\
\hline PCS & Initial AIS grade & $\mathrm{A}$ & $-6.1(-8.5 ;-3.77)$ & $-7.1(-9.5 ;-4.6)$ \\
& & $\mathrm{B}$ & $-4.5(-7.3 ;-1.6)$ & $-5.1(-7.6 ;-2.7)$ \\
& & $\mathrm{C}$ & $-3.4(-6.3 ;-0.4)$ & $-4.3(-6.8 ;-1.8)$ \\
$\mathrm{MCS}$ & $\mathrm{D}$ & Reference value & Reference category \\
& Initial AIS grade & $\mathrm{A}$ & $3.9(1.4 ; 6.3)$ & $3.2(0.1 ; 6.2)$ \\
& & $\mathrm{B}$ & $1.5(-1.7 ; 4.7)$ & $1.4(-2.1 ; 4.8)$ \\
& $\mathrm{C}$ & $0.1(-2.8 ; 2.9)$ & $-0.2(-3.2 ; 2.8)$ \\
& $\mathrm{D}$ & Reference category & Reference category \\
\hline
\end{tabular}

PCS physical component score, $M C S$ mental component score, $C I$ confidence interval

*Adjusted for age, gender, neurological status, presence of traumatic brain injury, burden of comorbidities (CCI), level of education, household income, employment status and household status the opposite direction (more severe AIS with higher MCS) (Table 4). This model was significant $\left(p=10^{-3}\right)$ and explained $11 \%$ of the variance in $\operatorname{MCS}\left(R^{2}=0.114\right)$.

\section{Discussion}

Cervical TSCI can result in severe functional limitations and deterioration in physical, emotional and social areas of health. To our knowledge, this is the first study to document general expectations in terms of QOL using the SF-36v2 questionnaire, according to the initial severity of the TSCI and taking into account other relevant clinical variables available at admission to acute care. This study showed that the initial AIS grade was significantly associated with PCS and MCS in the subacute period following a cervical TSCI. This study also suggests that the severity of the injury influences PCS and MCS differently.

In accordance with previous studies [12-14], a more severe AIS grade of cervical TSCI was associated with lower PCS in our study, indicating that physical QOL is significantly better with substantial preserved motor function. Completeness of the TSCI-assessed from the AIS grade-reflects the degree of the neurological deficits and potential for recovery [25]. It is also proportionally associated with resulting functional limitations [2], which may limit the level of participation of an individual in various activities [26]. Improvement in physical abilities, such as $\mathrm{arm} / \mathrm{hand}$ function and ability to ambulate independently, is one of the most important priorities for patients after an SCI, as it fosters independence, participation, and consequently affects positively QOL [27].

Conversely, more severe AIS grade was negatively associated with MCS. Interestingly, $13.4 \%$ of individuals with cervical TSCI reported a MCS higher than the average reported for the general Canadian population. This observation might seem counterintuitive, but previous studies have showed similar results for the SCI population [28, 29]. Our finding could be explained in part by the following hypotheses. First, the algorithm for computing the SF-36 summary scores may have contributed to this result since PCS and MCS are both calculated from various physical and mental domains, and are thus negatively correlated [30]. Calculation of PCS involves positive weights for physical domains (physical functioning, role-physical, bodily pain, general health and vitality scales), but also negative weights for mental domains (social functioning, role-emotional and emotional well-being scales) [30]. As a result, for two individuals with the same physical domain subscores, the PCS will be higher in the subject with lower mental domain subscores, as mental domain subscores negatively weigh the PCS [30]. This highlights the importance of interpreting component scores of the SF-36v2 questionnaire in combination with domain scores [31]. Accordingly in Table 3, vitality/role emotional and mental health scores were relatively higher in individuals with complete AIS A cervical TSCI, reinforcing that individuals with more severe TSCI may develop higher mental QOL.

Second, the relatively high MCS observed in some patients is also in agreement with previous studies showing that QOL could be discordant with the level of disabilities when using other QOL questionnaires [32, 33]. Individual characteristics may also contribute to the fact that some patients with neurological deficits may report good QOL despite severe disability. As the common understanding of a good QOL implies good health and a sense of well being, it seems intuitive that disabled individuals experience poorer QOL due to their limitations and role performance [33]. Accordingly, the concept of the 'disability paradox' has developed [33]. The disability paradox highlights the importance of personal experience with disability in defining the self, one's view of the world, social context and social relationships. Some individuals with disabilities may be able to produce and maintain a sense of balance between the body (physical function dimensions), mind (rational and intellectual capacities of the self) and spirit (having a purpose of life extending beyond the self), and therefore report good QOL despite their major disabilities. Some individuals 
may achieve this process through rediscovering spirituality in giving them strength, direction and meaning in life. Some individuals will develop a deep need to give and get involved in reciprocal relationships, or compare themselves with others in similar conditions providing positive or negative role models $[32,33]$. As suggested by Albrecht et al. [33], individuals experiencing disability can find an enriched meaning in their lives secondary to the disability condition, and may reconstitute personal meaning in their social roles [33]. For instance, some individuals may find satisfaction in using available resources to conquer each day challenges and help others sustaining similar disabilities. In some countries, more severe disability may also lead to higher transfer incomes (compensation payments from insurances or government), which could potentially influence perceived QOL $[34,35]$. On the other hand, individuals sustaining milder neurological deficits may experience unanticipated medical/psychological challenges (such as pain and higher depressive symptoms), and be more inclined to report lower QOL based on functional and neurological outcomes [36].

Rehabilitation approaches targeting improvement of QOL following a cervical TSCI may thus be adapted based on the initial severity of the injury. While all patients require education and should be followed by a multidisciplinary team addressing the emotional and cognitive issues after a TSCI [20, 37], this study suggests that the need for psychological support should not be underestimated in individuals with less severe neurological deficits (AIS D cervical TSCI). These individuals can benefit from a holistic approach focussing on developing a harmonious set of relationships within the person's social and environmental context at least as much as individuals with more severe deficits.

Overall, patients in our study reported decreased QOL when compared to the general Canadian population on all eight domains, as well as on the PCS and MCS of the SF$36 \mathrm{v} 2$, regardless of the initial severity of the neurological impairment. This is consistent with previous literature reporting a negative impact of the severity of the chronic neurological deficit on the QOL, especially for physical domains [12-14, 38]. However, the PCS of one patient with AIS C tetraplegia initially after the TSCI was higher than the mean values reported for the general Canadian population, despite the lack of improvement in neurological status during follow-up [24]. This supports that numerous factors other than the severity of the TSCI also influence QOL [27, 39].

\section{Limitations}

One of the main limitations of this study is the small number of patients from a single hospital centre, limiting its generalizability. The loss to follow-up reaching $37 \%$ is also a recognized limitation. However, baseline characteristics of losses to follow-up were similar to those completing the study, although patients lost to follow-up were older and less likely to be active workers. Older age is typically associated with decreased mobility, which may explain the difficulty to comply with scheduled follow-up visits. A total of $17 \%$ individuals lost to follow-up did not provide their working status, in comparison to one patient in the final cohort with adequate follow-up. Consequently, our findings are mainly applicable to younger active workers.

The authors acknowledge that the relationship between TSCI severity and MCS is complex. Because QOL is a multidimensional dynamic process [20, 40], clinical evolution may certainly influence QOL later in the process, in addition to personality, mood state, coping, pain and environmental factors [20]. This may explain the relatively low percentage of variance explained by the MCS model, when compared to the PCS model. Since the aim of this study was to help clinicians estimate QOL according to the initial evaluation following a cervical TSCI, factors related to clinical evolution were not considered. However, this study may be used by the medical and rehabilitation team to counsel patients about their expectations in QOL early during the acute care, and optimize modifiable factors influencing QOL during the rehabilitation process $[26,32]$.

The period of time after injury can also be related to QOL, as previous studies showed its effect on adjustment after TSCI [40]. Approximately $75 \%$ of our patients were administered the SF-36 12 months post-injury, while remaining patients were assessed 6 months post-SCI. However, time to follow-up is unlikely to have significantly biased the results for two different reasons. First, Table 1 shows that the baseline characteristics were similar between patients seen after 6 months vs. 12 months follow-up. Second, additional univariate linear regression analyses involving the timing of follow-up and MCS or PCS did not show any significant relationship $(p=0.81$ for MCS and $p$ $=0.44$ for PCS). Finally, Mortenson et al. [40] previously showed that QOL scores were not significantly different between 3 months and 15 months post-SCI.

\section{Conclusions}

This study suggests that a severe initial AIS grade is associated with lower PCS and higher MCS in the subacute phase following cervical TSCI. Severe neurological deficits may limit functional independence, participation and perception of general health, and consequently decrease the PCS. However, psychological challenges represented by such injury are not necessarily associated to the importance 
of physical limitations, as individuals with less severe AIS grades may present lower MCS. Our findings could be useful for clinicians working in acute care settings to improve early counselling between the medical/surgical and rehabilitation teams, along with the patients and family, in order to set realistic goals early during the first days after the injury. Overall, individuals with cervical TSCI present lower subacute QOL scores compared to the general Canadian population, when evaluated using the SF-36 questionnaire.

\section{Data sharing}

According to our ethic board committee, public data sharing is not allowed. Most of our data is included in the Rick Hansen Registry. However, specific request for confidential data sharing can be addressed to the corresponding author.

Author contributions ARD contributed to the design of the study, data collection, statistical analysis, data interpretation and article redaction. CT contributed to the data collection and statistical analysis. JMMT contributed to the design of the study, data interpretation and article preparation.

Funding This research was funded by the US Department of Defense Spinal Cord Injury Research Program. Part of the data was collected through the Rick Hansen Spinal Cord Injury Registry.

\section{Compliance with ethical standards}

Conflict of interest The authors declare that they have no conflict of interest.

\section{References}

1. Sezer N, Akkus S, Ugurlu FG. Chronic complications of spinal cord injury. World J Orthop. 2015;6:24-33.

2. Richard-Denis A, Feldman D, Thompson C, Mac-Thiong JM. Prediction of functional recovery six months following traumatic spinal cord injury during acute care hospitalization. J Spinal Cord Med. 2017;41:1-9.

3. Consortium for Spinal Cord M. Early acute management in adults with spinal cord injury: a clinical practice guideline for health-care professionals. J Spinal Cord Med. 2008;31:403-79.

4. Kirshblum SC, O'Connor KC. Predicting neurologic recovery in traumatic cervical spinal cord injury. Arch Phys Med Rehabil. 1998;79:1456-66.

5. van Middendorp JJ, Hosman AJ, Donders AR, Pouw MH, Ditunno JF Jr, Curt A, et al. A clinical prediction rule for ambulation outcomes after traumatic spinal cord injury: a longitudinal cohort study. Lancet. 2011;377:1004-10.

6. Organization WH Health statistics and information systems. WHOQOL: measuring Quality of life: WHO; 2018. http://www. who.int/healthinfo/survey/whoqol-qualityoflife/en/. Accessed 15 Apr 2018.

7. Diener E, Emmons RA, Larsen RJ, Griffin S. The satisfaction with life scale. J Pers Assess. 1985;49:71-5.
8. Veenhoven R. Social conditions for human happiness: a review of research. Int J Psychol. 2015;50:379-91.

9. Wilson JR, Grossman RG, Frankowski RF, Kiss A, Davis AM, Kulkarni AV, et al. A clinical prediction model for long-term functional outcome after traumatic spinal cord injury based on acute clinical and imaging factors. $J$ Neurotrauma. 2012;29:2263-71.

10. Dijkers M. Quality of life after spinal cord injury: a meta analysis of the effects of disablement components. Spinal Cord. 1997;35:829-40.

11. Cushman DM, Thomas K, Mukherjee D, Johnson R, Spill G. Perceived quality of life with spinal cord injury: a comparison between emergency medicine and physical medicine and rehabilitation physicians. PM R. 2015;7:962-9.

12. Lidal IB, Veenstra M, Hjeltnes N, Biering-Sorensen F. Healthrelated quality of life in persons with long-standing spinal cord injury. Spinal Cord. 2008;46:710-5.

13. Forchheimer M, McAweeney M, Tate DG. Use of the SF-36 among persons with spinal cord injury. Am J Phys Med Rehabil. 2004;83:390-5.

14. Kivisild A, Sabre L, Tomberg T, Ruus T, Korv J, Asser T, et al. Health-related quality of life in patients with traumatic spinal cord injury in Estonia. Spinal Cord. 2014;52:570-5.

15. Quebec Gd. Quebec handy numbers. In: Quebec Idlsd, editor. Bibliothèque et Archives nationales du Quebec ed: Institut de la statistique du Quebec; 2017.

16. Kirshblum SC, Burns SP, Biering-Sorensen F, Donovan W, Graves DE, Jha A, et al. International standards for neurological classification of spinal cord injury (revised 2011). J Spinal Cord Med. 2011;34:535-46.

17. Baker SP, O'Neill B. The injury severity score: an update. J Trauma. 1976;16:882-5.

18. Charlson M, Wells MT, Ullman R, King F, Shmukler C. The Charlson comorbidity index can be used prospectively to identify patients who will incur high future costs. PLoS ONE. 2014;9: e112479.

19. Chappell PWS. Quality of life following spinal cord injury for 2040 Year old males living in Sri Lanka. Asia Pac Disabil Rehabil J. 2003;14:168-78.

20. Post M, Noreau L. Quality of life after spinal cord injury. J Neurol Phys Ther. 2005;29:139-46.

21. Ware JE Jr, Sherbourne CD. The MOS 36-item short-form health survey (SF-36). I. Conceptual framework and item selection. Med Care. 1992;30:473-83.

22. RA A. When to use the Benferroni correction. Ophtalmic Physiol Opt. 2014;34:502-08.

23. Perneger TV. What's wrong with Bonferroni adjustments. BMJ. 1998;316:1236-8.

24. Hopman WM, Towheed T, Anastassiades T, Tenenhouse A, Poliquin S, Berger C, et al. Canadian normative data for the SF-36 health survey. Canadian Multicentre Osteoporosis Study Research Group. CMAJ. 2000;163:265-71.

25. Fawcett JW, Curt A, Steeves JD, Coleman WP, Tuszynski MH, Lammertse D, et al. Guidelines for the conduct of clinical trials for spinal cord injury as developed by the ICCP panel: spontaneous recovery after spinal cord injury and statistical power needed for therapeutic clinical trials. Spinal Cord. 2007;45:190-205.

26. Noreau L, Fougeyrollas P, Post M, Asano M. Participation after spinal cord injury: the evolution of conceptualization and measurement. J Neurol Phys Ther. 2005;29:147-56.

27. Erosa NA, Berry JW, Elliott TR, Underhill AT, Fine PR. Predicting quality of life 5 years after medical discharge for traumatic spinal cord injury. Br J Health Psychol. 2014;19:688-700.

28. Haran MJ, Lee BB, King MT, Marial O, Stockler MR. Health status rated with the Medical Outcomes Study 36-Item Short- 
Form Health Survey after spinal cord injury. Arch Phys Med Rehabil. 2005;86:2290-5.

29. Abrantes-Pais Fde N, Friedman JK, Lovallo WR, Ross ED. Psychological or physiological: why are tetraplegic patients content? Neurology. 2007;69:261-7.

30. Farivar SS, Cunningham WE, Hays RD. Correlated physical and mental health summary scores for the SF-36 and SF-12 Health Survey, V.I. Health Qual Life Outcomes. 2007;5:54.

31. Taft C, Karlsson J, Sullivan M. Do SF-36 summary component scores accurately summarize subscale scores? Qual life Res. 2001;10:395-404.

32. Bonanno GA, Kennedy P, Galatzer-Levy IR, Lude P, Elfstrom ML. Trajectories of resilience, depression, and anxiety following spinal cord injury. Rehabil Psychol. 2012;57:236-47.

33. Albrecht GL, Devlieger PJ. The disability paradox: high quality of life against all odds. Soc Sci Med. 1999;48:977-88.

34. Diener ESE. Measuring quality of life: economic, social, and subjective indicators. Soc Indic Res. 1997;40:189-216.
35. Clayton KS, Chubon RA. Factors associated with the quality of life of long-term spinal cord injured persons. Arch Phys Med Rehabil. 1994;75:633-8.

36. Ames H, Wilson C, Barnett SD, Njoh E, Ottomanelli L. Does functional motor incomplete (AIS D) spinal cord injury confer unanticipated challenges? Rehabil Psychol. 2017;62:401-6.

37. Martz E, Livneh H, Priebe M, Wuermser LA, Ottomanelli L. Predictors of psychosocial adaptation among people with spinal cord injury or disorder. Arch Phys Med Rehabil. 2005;86:1182-92.

38. Westgren N, Levi R. Quality of life and traumatic spinal cord injury. Arch Phys Med Rehabil. 1998;79:1433-9.

39. Ebrahimzadeh MH, Soltani-Moghaddas SH, Birjandinejad A, Omidi-Kashani F, Bozorgnia S. Quality of life among veterans with chronic spinal cord injury and related variables. Arch Trauma Res. 2014;3:e17917.

40. Mortenson WB, Noreau L, Miller WC. The relationship between and predictors of quality of life after spinal cord injury at 3 and 15 months after discharge. Spinal Cord. 2010;48:73-9. 